\title{
Laterality of breast cancer at Dr George Mukhari Academic Hospital
}

\author{
DH Mokone-Fatunla, ${ }^{1}$ MZ Koto, ${ }^{1}$ JHR Becker, ${ }^{1}$ M Bondo, ${ }^{1}$ S Mundawarara ${ }^{2}$ \\ ${ }^{I}$ Department of Surgery, Faculty of Health Sciences, School of Medicine, Sefako Makgatho Health Sciences University, \\ South Africa \\ ${ }^{2}$ Department of Surgery, Natalspruit Hospital, South Africa
}

Corresponding author: Dr D H Mokone-Fatunla (mathilda.howard@smu.ac.za)

\begin{abstract}
Background: The purpose of this descriptive study was to determine and compare the incidence of left-sided and rightsided breast cancer at Dr George Mukhari Academic Hospital from January 2000 to June 2016. It aimed to determine if there was a significant variation in laterality of breast cancer at our institution.

Method: A retrospective study. Medical records of breast cancer (BC) patients who were newly diagnosed from January 2000 to June 2016 were reviewed. Emphasis was on biopsy results (histology and/or cytology) and/or history of chemotherapy, and breast cancer laterality.

Results: Out of 1482 patients, 1427 had unilateral BC and 55 (3.7\%) bilateral cancer. A total of 789 (55.3\%) patients had left-sided breast cancer (LSBC) and $638(44.7 \%)$ had right BC. Left BC was $10.6 \%$ more common than right $\mathrm{BC}$ with a left to right laterality ratio (LRR) of 1.24 . There was a statistically significant relationship between laterality and stage $(\mathrm{p}=0.050)$, with the right breast having more advanced stage cancers $(88.7 \%)$ compared to the left breast $(85 \%)$. There was no statistically significant difference between age, site and histological type of BC and laterality $(p=0.740, p=0.052$, $\mathrm{p}=0.394$ respectively).

Conclusion: Left to right BC excess does exist in patients that were newly diagnosed at Dr George Mukhari Academic Hospital, South Africa, from January 2000 to June 2016.
\end{abstract}

S Afr J Surg 2019;57(3)

$\underline{\text { http://dx.doi.org/10.17159/2078-5151/2019/v57n3a2859 }}$

\section{Introduction}

Breast cancer is the most common cancer in women globally and in South Africa, where it is followed by cervical cancer. ${ }^{1,2}$ It is the second most common cancer worldwide after lung cancer. ${ }^{1}$ Breast cancer is the leading cause of cancer-related death in women in developing countries. ${ }^{1}$

Breast cancer has been reported to be more common on the left ${ }^{3-12}$ and in the upper outer quadrant (UOQ) of the breast. The reported ratio of left-sided to right-sided breast cancer (RSBC) ranges from $1.05: 1$ to $1.26: 1^{4,7,8,11-13}$; rather, BC is about $5 \%$ more likely to be diagnosed in the left than the right. . $^{3,5,7,8,11,12}$

The cause of this relative excess incidence of left to right breast cancer is not known. ${ }^{5}$ Various factors have been suggested. These include increased trauma to the left breast, breast feeding patterns (most women are right-handed and therefore frequently nurse on the right ${ }^{14}$ and larger size and density of the left breast compared to the right breast. ${ }^{4,6,15}$ It is also suggested that because the majority of women are righthanded, it is easier for them to examine and detect cancers in the left breast.
Some studies have shown that the laterality ratio varies linearly with age , $^{5,13,16}$ was evident only after the age of 45 years in Swedish women with invasive cancer ${ }^{13}$ and was higher in women over 60 years in Israel. ${ }^{9}$ A statistically significant left-sided lateralization was found only in premenopausal patients in a study by Dane et al. ${ }^{17}$ in 165 women at Atartuk University in Turkey. In a study of 419935 patients with unilateral BC from 26 population-based registries in the United States, by Perkins et al., ${ }^{3}$ a left to right predominance was found in all age groups and tumour types. In contrast to the studies mentioned above, Busk et al. ${ }^{7}$ found no significant variation with age in a study of 4139 cases taken from a Danish cancer registry from 1942-1946.

Some state that the left-to-right asymmetry depends on the location/quadrant in which BC occurs, and that it is only cancers situated in the UOQ that show this left-to-right ratio (LRR) excess. ${ }^{16}$ Perkins et al. ${ }^{3}$ found that cancers in the UOQ occurred with equal frequencies in both breasts, and that cancers in the lower quadrants were about $10 \%$ more likely to occur in the left breast.

A few studies ${ }^{8,10,17,18}$ found that, although right-sided breast cancer (RSBC) is less common than left cancer, it tends to be more aggressive. Fatima et al. ${ }^{10}$ studied 384 BC cases 
from Karachi Institute, Turkey and concluded that RSBC has a more aggressive behaviour, with extensive and earlier appearance of bone metastasis, at a relatively younger age, with smaller primary tumours and receptor(s) negativity. Dane et al. ${ }^{17}$ concluded that both total number as well as number of metastatic axillary lymph nodes were higher in patients with right-sided compared to left BC. Dmitrenko et al. ${ }^{18}$ found that RSBC had significantly higher KI67 index (surrogate marker for cell proliferation and thus tumour aggressiveness), compared to left cancers in two age groups, $\leq 49$ years and 50-59 years.

Other studies ${ }^{4,19,20}$ suggested that left $\mathrm{BC}$ is not only more common than right $\mathrm{BC}$, but also had a higher incidence of radiation-induced cardiac disease like ischaemic heart disease and congestive cardiac failure and a higher incidence of cardiac mortality. Rutter et al. ${ }^{21}$ and Harris et al. ${ }^{22}$ found no association between $\mathrm{BC}$ laterality and radiation induced mortality and/or over-all survival.

The aim of this study was to determine if this relative excess incidence of left-to-right breast cancer exists at our institution and, if it does exist, to determine the left-to-right laterality ratio and compare it to other studies in literature.

\section{Methods}

A retrospective study. Medical records (files and histology results) of all patients who were newly diagnosed with $\mathrm{BC}$ at our Breast Oncology Clinic and Surgical Out-Patients Department (SOPD) from January 2000 to June 2016 were reviewed. Information on age at diagnosis, gender, laterality of BC, involved quadrant(s), stage and type of BC (diagnosed by histology and/or cytology) was recorded. Patients whose biopsy results were not stated in the hospital files and could not be traced through laboratory records, but were clinically diagnosed with $\mathrm{BC}$ and received chemotherapy, were included in the study.

The prevalence of left and right breast cancer was determined and expressed as a ratio.

\section{Statistical Analyses}

The data were captured in an Excel spread sheet. The statistical analyses were performed on SAS (SAS Institute Inc, Cary, NC, USA), Release 9.4. Mean and median values were calculated for age. Categorical variables were summarized by frequency counts and percentage calculations. Percentages were compared by the chi-squared test.

\section{Results}

A total of 1482 patients were analysed, 1450 (97.8\%) were females and $32(2.2 \%)$ males. These included $1461(98.6 \%)$ black patients and $21(1.4 \%)$ white patients. Age ranged between 21 and 96 years, with a mean of 54.96 with a standard deviation (STD) of 14.01. Age was not stated in 46 (3.2\%) patients.
Of the patients, $1427(96.3 \%)$ had unilateral BC and 55 (3.7\%) had bilateral cancer. Among the unilateral cancers, 789 $(55.3 \%)$ were diagnosed in the left breast and $638(44.7 \%)$ in the right. Left $\mathrm{BC}$ was $10.6 \%$ more common than right $\mathrm{BC}$, with a LRR of 1.24

\section{Age and Laterality}

The age of patients with unilateral breast cancer ranged from 21 to 96 years. Patients with left BC had the same age range as above, with mean of 50.79 and STD of 14.01. For right $\mathrm{BC}$, the age ranged from 26 to 96 years with a mean of 55.26 and a standard deviation of 14.02 . The majority of patients fell under age groups 40-49 (25.1\%), 50-59 (24.0\%) and 60$69(20.9 \%)$. There was no statistically significant difference between left and right $\mathrm{BC}$ in relation to age $(\mathrm{p}=0.740)$. (See Figure 1)

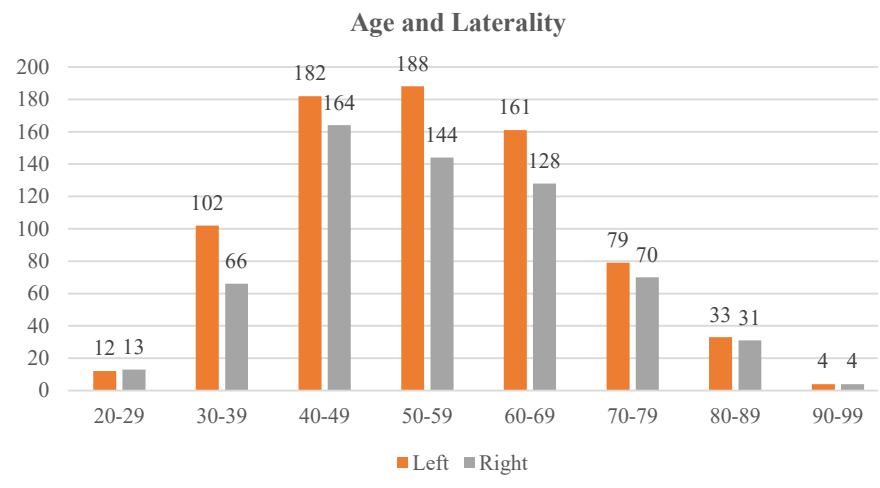

Figure 1: Age and laterality

\section{Site}

Tumour location was not stated in 337 (23.6\%) patients with unilateral BC. In 440/1090(40.4\%) patients, the cancer was in the upper outer quadrant (UOQ), $112(10.3 \%)$ in the upper inner quadrant (UIQ), $59(5.4 \%)$ in the lower outer quadrant (LOQ), 29 (2.7\%) in the lower inner quadrant (LIQ), $110(10.1 \%)$ retro-areolar, $123(11.3 \%)$ in all quadrants, $110(10.1 \%)$ in both upper quadrants, $47(4.3 \%)$ in both lower quadrants, $47(4.3 \%)$ in lateral quadrants, and 13 $(1.2 \%)$ in the inner quadrant. Out of 598 left BCs analysed for site, $238(39.8 \%)$ were in the UOQ, compared to 202 (41.1\%) out of 492 RSBC. Overall, there was no significant statistical relationship between site and laterality $(\mathrm{p}=0.052)$.

\section{(See Table 2)}

\section{Stage}

Tumour stage was not stated in $118(8.3 \%)$ patients with unilateral BC. Out of 1309 patients who were analysed for stage, $19(1.5 \%)$ had carcinoma in situ, $37(2.8 \%)$ were in stage $1,119(9.1 \%)$ in stage $2 a, 197(15.0 \%)$ in stage $2 b$ and $258(19,7 \%)$ in stage $3 \mathrm{a}$. The majority of patients, that is 404 (30.9\%), had stage $3 \mathrm{~b}$ cancer, $264(20.2 \%)$ had stage 4 cancer with only 11 patients $(0.8 \%)$ who had stage $3 \mathrm{c}$ disease. 
Table 1: Laterality and cancer characteristics

\begin{tabular}{|c|c|c|c|c|c|c|}
\hline \multirow[t]{2}{*}{ Characteristics } & \multirow{2}{*}{$\begin{array}{c}\text { Total } \\
\mathrm{N}\end{array}$} & \multicolumn{2}{|c|}{ Left ca } & \multicolumn{2}{|c|}{ Right ca } & \multirow[t]{2}{*}{$\overline{p \text { value }}$} \\
\hline & & $\mathbf{N}$ & $\%$ & $\mathbf{N}$ & $\%$ & \\
\hline Patients & 1427 & 789 & 55.3 & 638 & 44.7 & 0.459 \\
\hline Females & 1397 & 770 & 97.6 & 627 & 98.3 & 0.459 \\
\hline Males & 30 & 19 & 2.4 & 11 & 1.7 & 0.459 \\
\hline Site & & & & & & 0.070 \\
\hline Not known & 337 & 191 & 24.2 & 146 & 22.9 & 0.573 \\
\hline UOQ & 440 & 238 & 30.2 & 202 & 31.7 & 0.564 \\
\hline UIQ & 112 & 59 & 7.5 & 53 & 8.3 & 0.621 \\
\hline LOQ & 59 & 35 & 4.4 & 24 & 3.8 & 0.593 \\
\hline LIQ & 29 & 13 & 1.6 & 16 & 2.5 & 0.264 \\
\hline Retro-areolar & 110 & 70 & 8.9 & 40 & 6.3 & 0.073 \\
\hline All & 123 & 57 & 7.2 & 66 & 10.3 & 0.046 \\
\hline Upper & 110 & 55 & 7.0 & 55 & 8.6 & 0.272 \\
\hline Lower & 47 & 32 & 4.0 & 15 & 2.4 & 0.075 \\
\hline Outer & 47 & 29 & 3.7 & 18 & 2.8 & 0.456 \\
\hline Inner & 13 & 10 & 1.3 & 3 & 0.5 & 0.162 \\
\hline Stage & & & & & & 0.139 \\
\hline Not known & 118 & 64 & 8.1 & 54 & 8.5 & 0.847 \\
\hline $0-2 \mathrm{a}$ & 175 & 109 & 13.8 & 66 & 10.3 & 0.051 \\
\hline $2 b-4$ & 1134 & 616 & 78.1 & 518 & 81.2 & 0.166 \\
\hline Histology/Cytology & & & & & & 0.520 \\
\hline Not known & 124 & 69 & 8.7 & 55 & 8.6 & 1.000 \\
\hline DCIS & 19 & 11 & 1.4 & 8 & 1.3 & 1.000 \\
\hline Ductal carcinoma & 1105 & 617 & 78.2 & 488 & 76.5 & 0.446 \\
\hline Lobular carcinoma & 94 & 48 & 6.1 & 46 & 7.2 & 0.393 \\
\hline Tubulo-lobular carcinoma & 34 & 22 & 2.8 & 12 & 1.9 & 0.298 \\
\hline Adenocarcinoma & 41 & 18 & 2.3 & 23 & 3.6 & 0.153 \\
\hline Other & 10 & 4 & 0.5 & 6 & 0.9 & 0.357 \\
\hline ER & & & & & & 0.239 \\
\hline Not known & 587 & 347 & 44.0 & 240 & 37.6 & 0.017 \\
\hline Positive & 492 & 250 & 31.7 & 242 & 37.9 & 0.014 \\
\hline Negative & 348 & 192 & 24.3 & 156 & 24.5 & 1.000 \\
\hline PR & & & & & & 0.121 \\
\hline Not known & 601 & 350 & 44.3 & 251 & 39.3 & 0.059 \\
\hline Positive & 396 & 205 & 26.0 & 191 & 29.9 & 0.108 \\
\hline Negative & 430 & 234 & 29.7 & 196 & 30.7 & 0.685 \\
\hline HER2 & & & & & & 0.106 \\
\hline Not known & 627 & 366 & 46.4 & 261 & 40.9 & 0.042 \\
\hline Positive & 232 & 131 & 16.6 & 101 & 15.8 & 0.719 \\
\hline Negative & 510 & 261 & 33.1 & 249 & 39.0 & 0.023 \\
\hline Equivocal & 58 & 31 & 3.9 & 27 & 4.2 & 0.789 \\
\hline KI67 & & & & & & 0.0003 \\
\hline Not known & 930 & 550 & 69.7 & 380 & 59.6 & $<0.001$ \\
\hline$<20$ & 288 & 142 & 18.0 & 146 & 22.9 & 0.024 \\
\hline$>20$ & 209 & 97 & 12.3 & 112 & 17.5 & 0.007 \\
\hline
\end{tabular}




\begin{tabular}{lccccccc} 
Grade & & & & $\mathbf{0 . 9 8 6}$ \\
\hline Not known & 923 & 510 & 64.6 & 413 & 64.7 & 1.000 & 0.793 \\
1 & 61 & 35 & 4.4 & 26 & 97 & 15.2 & 0.882 \\
2 & 214 & 117 & 14.8 & 102 & 16.0 & 1.000
\end{tabular}

$\mathrm{NK}=$ Not known

Table 2: Patient and cancer characteristics (excluding missing information)

\begin{tabular}{|c|c|c|c|c|c|c|}
\hline \multirow[t]{2}{*}{ Characteristics } & \multirow{2}{*}{$\begin{array}{l}\text { Total } \\
\mathbf{N}\end{array}$} & \multicolumn{2}{|c|}{ Left ca } & \multicolumn{2}{|c|}{ Right ca } & \multirow[t]{2}{*}{ p value } \\
\hline & & $\mathbf{N}$ & $\%$ & $\mathbf{N}$ & $\%$ & \\
\hline Site & & & & & & 0.052 \\
\hline UOQ & 440 & 238 & 39.8 & 202 & 41.1 & 0.710 \\
\hline UIQ & 112 & 59 & 9.9 & 53 & 10.8 & 0.689 \\
\hline LOQ & 59 & 35 & 5.9 & 24 & 4.9 & 0.504 \\
\hline LIQ & 29 & 13 & 2.2 & 16 & 3.2 & 0.345 \\
\hline Retro-areolar & 110 & 70 & 11.7 & 40 & 8.1 & 0.055 \\
\hline All & 123 & 57 & 9.5 & 66 & 13.4 & 0.054 \\
\hline Upper & 110 & 55 & 9.2 & 55 & 11.2 & 0.313 \\
\hline Lower & 47 & 32 & 5.3 & 15 & 3.0 & 0.072 \\
\hline Outer & 47 & 29 & 4.8 & 18 & 3.7 & 0.371 \\
\hline \multirow[t]{2}{*}{ Inner } & 13 & 10 & 1.7 & 3 & 0.6 & 0.160 \\
\hline & 1090 & 598 & & 492 & & \\
\hline Stage & & & & & & 0.050 \\
\hline $0-2 \mathrm{a}$ & 175 & 109 & 15.0 & 66 & 11.3 & 0.050 \\
\hline \multirow[t]{2}{*}{$2 b-4$} & 1134 & 616 & 85.0 & 518 & 88.7 & 0.050 \\
\hline & 1309 & 725 & & 584 & & \\
\hline Histology/Cytology & & & & & & 0.394 \\
\hline DCIS & 19 & 11 & 1.5 & 8 & 1.4 & 1.000 \\
\hline Ductal & 1105 & 617 & 85.7 & 488 & 83.7 & 0.352 \\
\hline Lobular & 94 & 48 & 6.7 & 46 & 7.9 & 0.451 \\
\hline Tubulo-lobular & 34 & 22 & 3.1 & 12 & 2.1 & 0.297 \\
\hline Adenocarcinoma & 41 & 18 & 2.5 & 23 & 3.9 & 0.152 \\
\hline \multirow[t]{2}{*}{ Other } & 10 & 4 & 0.6 & 6 & 1.0 & 0.357 \\
\hline & 1303 & 720 & & 583 & & \\
\hline ER & & & & & & 0.233 \\
\hline Positive & 492 & 250 & 56.6 & 242 & 60.8 & 0.233 \\
\hline \multirow[t]{2}{*}{ Negative } & 348 & 192 & 43.4 & 156 & 39.2 & 0.233 \\
\hline & 840 & 442 & & 398 & & \\
\hline PR & & & & & & 0.485 \\
\hline Positive & 396 & 205 & 46.7 & 191 & 49.4 & 0.485 \\
\hline \multirow[t]{2}{*}{ Negative } & 430 & 234 & 53.3 & 196 & 50.6 & 0.485 \\
\hline & 826 & 439 & & 387 & & \\
\hline HER2 & & & & & & 0.407 \\
\hline Positive & 232 & 131 & 31.0 & 101 & 26.8 & 0.212 \\
\hline Negative & 510 & 261 & 61.7 & 249 & 66.0 & 0.211 \\
\hline \multirow[t]{2}{*}{ Equivocal } & 58 & 31 & 7.3 & 27 & 7.2 & 1.000 \\
\hline & 800 & 423 & & 377 & & \\
\hline
\end{tabular}




\begin{tabular}{lcccccc} 
KI67 & \multicolumn{2}{c}{} & & $\mathbf{0 . 5 2 6}$ \\
\hline$\leq 20$ & 288 & 142 & 59.4 & 146 & 56.6 & 0.526 \\
$>20$ & 209 & 97 & 40.6 & 112 & 43.4 & 0.526 \\
& 497 & 239 & & 258 & & \\
\hline Grade & & & & 26 & 11.6 & 0.784 \\
\hline 1 & 61 & 35 & 12.5 & 97 & 43.1 & 0.856 \\
2 & 214 & 117 & 41.9 & 102 & 45.3 & 1.000 \\
3 & 229 & 127 & 45.5 & 225 & &
\end{tabular}

The patients were further grouped into early BC (Stage $0-2 a)$ and advanced BC (Stage 2b-4). Of these 175 (13.4\%) had early BC and 1134 (86.6\%) had advanced disease. When further analysed according to laterality, 109 (15.0\%) of left BCs were early and $616(85 \%)$ were advanced. With RSBC, 66 (11.3\%) patients had early disease and 518 (88,7\%) had advanced disease. There was a statistically significant difference between left and RSBC $(p=0.050)$. (See Table 2)

\section{Histological/Cytological type and Laterality}

Type of BC was not stated in 124 out of 1427 (8.7\%) patients. Out of those who were analysed, $19(1.5 \%)$ had ductal carcinoma in situ (DCIS). The majority of patients, namely $1105(84.8 \%)$, had invasive ductal carcinoma. This number included $85.7 \%$ (617) of LSBC and of $83.7 \%$ (488) RSBC. A total of $94(7.2 \%)$ patients had invasive lobular carcinoma, 34 (2.6\%) tubulo-lobular carcinoma, and $41(3.1 \%)$ reported as adenocarcinoma (not specified if invasive ductal or invasive lobular carcinoma). Other tumours that included 4 sarcomas, 2 lymphomas and 4 squamous cell carcinomas comprised $0.8 \%$. There was no statistically significant relationship between type of cancer and laterality $(\mathrm{p}=0.394)$.

(See Table 2)

\section{Sub-types of invasive ductal carcinoma}

Invasive ductal carcinoma was further divided into subtypes. Of the patients, $963(87.2 \%)$ had invasive ductal carcinoma not otherwise specified (NOS); 16 (1.4\%) had papillary carcinoma, $47(4.3 \%)$ medullary carcinoma, $50 \quad(4.5 \%)$ mucinous carcinoma, and $29(2.6 \%)$ had either tubular, inflammatory, cribriform or comedo carcinoma.

\section{Oestrogen and progesterone receptor}

Only 840 (58.9\%) of the patients were analysed for oestrogen receptor (ER) status. A total of 492 (58.6\%) patients had ER-positive tumours, 250 had left-sided and 242 right-sided cancer. (See Table 2).

Progesterone receptor (PR) status was reported in 826 $(57.9 \%)$ patients with unilateral breast cancer, and was positive in $396(47.9 \%)$ patients. There was no significant difference between left- and right-sided breast cancer and ER and/or PR ( $p=0.233, p=0.485$ respectively). (See Table 2 ).

\section{HER2}

Out of 1427 patients with unilateral BC, 43.9\% (627) did not have HER2 results. HER2 was positive in 232 out of 800 patients $(29.0 \%)$, negative in $510(63.8 \%)$ patients and equivocal in $58(7.2 \%)$ patients. (See Table 2).

Fluorescent in situ hybridisation (FISH) test was not done in the latter group.

\section{KI67 and tumour grade}

KI67 results were available in $497(34.8 \%)$ patients. It was less than or equal to $20 \%$ in 288 patients and greater than $20 \%$ in $209(42.1 \%)$ patients.

Tumour grade results were available in 504 (35.3\%) patients with unilateral breast cancer. Sixty-one (61) patients (12.1\%) had grade 1 cancer. A total of $214(42.5 \%)$ had grade 2 cancer and 229 (45.4\%) had grade 3 cancer. (See Table 2).

KI67 and cancer grade were not analysed according to age, stage or histological type.

\section{Molecular subtypes of breast cancer}

Of the patients with unilateral breast cancer, 701 (49.1\%) were analysed for molecular subtype. Of these, 230 (32.8\%) had luminal A cancer, 67 (9.6\%) had luminal B, 142 (20.3\%) had HER2 positive luminal B, $76(10.8 \%)$ had HER2 positive and $186(26.5 \%)$ triple negative cancer. (See Figure 2)

Molecular subtype was not analysed according to age, site and stage of breast cancer.

\section{Bilateral breast cancer}

Of the 55 patients who had bilateral breast cancer, 53 were females and 2 were males. Age ranged from 23 to 88 years. A total of $40(72.7 \%)$ patients had the cancer simultaneously and $15(27.3 \%)$ sequentially. Among the sequential cancers, 8 $(57.1 \%)$ started on the left and $6(42.3 \%)$ started on the right.

\section{Discussion}

We compared LSBC to RSBC at our institution from January 2000 to June 2016. This is the first study on breast cancer laterality in our institution and perhaps in South Africa. 


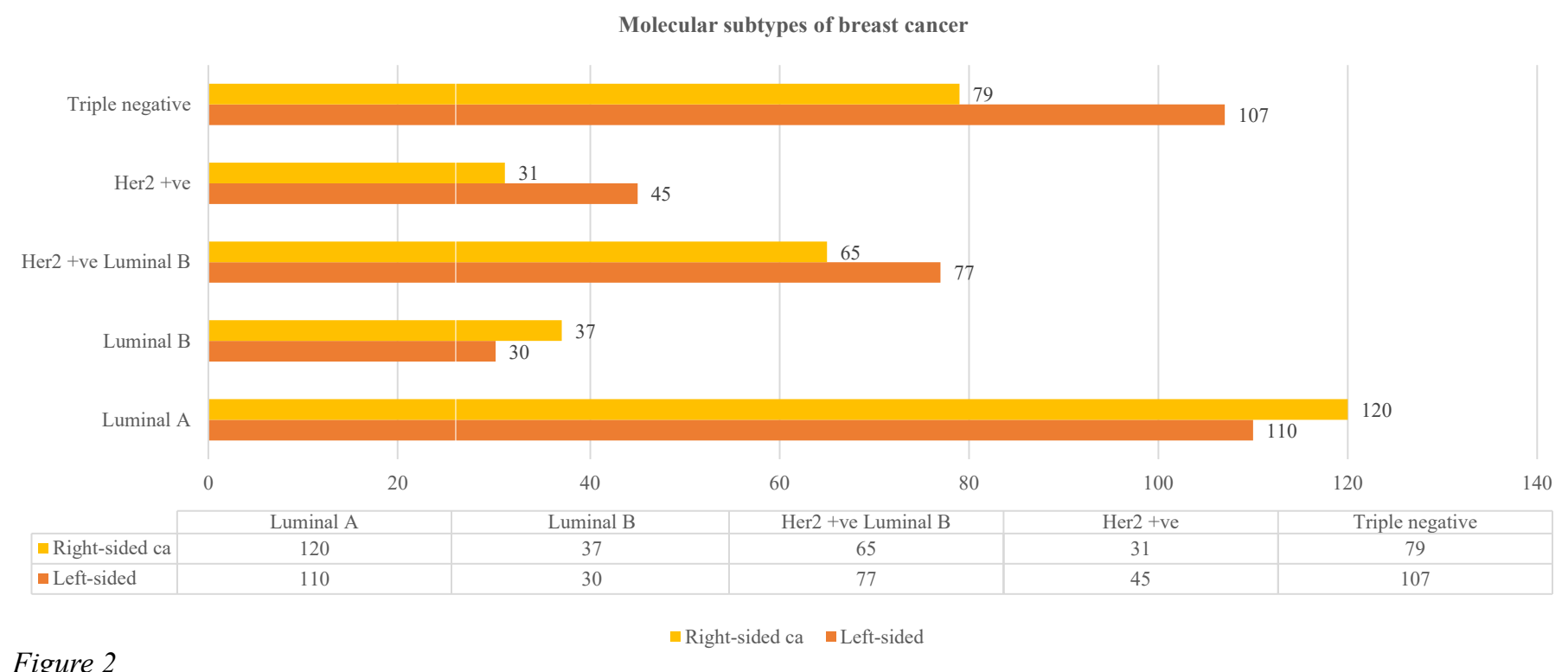

Figure 2

Our findings were that the relative excess incidence of left to right $\mathrm{BC}$ does exist. Breast cancer was $10.6 \%$ more common in the left than in the right breast. This was found to be $5 \%$ by Perkins et al. ${ }^{3}$ in their study of 26 population-based breast cancer registries in the USA. In the study by Zeeneldin et al., ${ }^{8}$ this figure was $7.28 \%$ in Egypt, $6.4 \%$ in a study by Tulinus et al. ${ }^{12}$ in Iceland, and $18 \%$ in Karachi, Pakistan, as reported by Fatima et al. ${ }^{10}$

The (LRR) was 1.24 in our study. It is comparable to 1.1 in a study by Busk et al., 1.16 in Zeeneldin et al. (1999 to 2007) and 1.44 in Fatima et al. Weiss et al. studied 250000 patients from a SEER programme in the USA from 1973 to 1992, and the LRR was 1.05 and 1.06 respectively for pre-invasive and invasive breast cancer. Roychoudhuri et al. ${ }^{4}$ found a LRR of 1.07 .

Laterality was not statistically analysed according to gender. Unlike in some studies in literature, ${ }^{5,9,13,16}$ in our study there was no association between laterality and age $(p=0.740)$. Our study showed a statistically significant association between laterality and stage, with the right breast having more advanced stage cancer compared to the left $(\mathrm{p}=0.050)$.

Due to the retrospective nature of the study, $23.6 \%$ of the patients were not assessed for tumour site. It was found that $39.8 \%$ and $41.1 \%$ of left and right $\mathrm{BC}$ respectively had tumours in the UOQ. Tumours of the UOQ were $43.3 \%$ in the left and $46.6 \%$ in the right in Zeneeldin et al. Overall in our study there was no significant relationship between laterality and site $(\mathrm{p}=0.052)$, and laterality and histological type $(\mathrm{p}=0.394)$.

The incidence of carcinoma in situ in this study was $1.5 \%$. It was $1.1 \%$ in a study done in Groote Schuur Hospital, Cape Town, South Africa, on DCIS by Mutebi et al. ${ }^{23}$ from 2005 to $2012,5 \%$ in a study by Amer et al. ${ }^{11}$ (2005-2012), 12.1\% (DCIS only) in Rutter et al. ${ }^{21}$ from 1998 to 2006. According to estimations from the American Cancer Association, ${ }^{24}$ carcinoma in situ was expected to account for $20 \%$ of new breast cancers diagnosed in 2015 .
The low incidence of carcinoma in situ in our study might be due to the retrospective nature of the study. It is important to note that in this study, in 118 out of $1303(7.2 \%)$ patients analysed for histological type of cancer, DCIS coexisted with invasive cancer. The studies on carcinoma in situ quoted above were also retrospective.

Due to the small number of patients analysed, we cannot comment on laterality and ER, PR, HER2 or tumour grade.

\section{Study limitations}

A retrospective study with missing information, affecting statistical analysis.

\section{Conclusion}

Left to right breast cancer excess does exist in breast cancer patients who were newly diagnosed at Dr George Mukhari Academic Hospital, South Africa, from January 2000 to June 2016. It was found to be $10.6 \%$ with a LRR of 1.24 .

A prospective study of laterality of breast cancer at our institution is suggested. Such study might provide answers to the difference between left and right breast cancer in terms of demographics, risk factors and cancer behaviour. In our study, the only statistically significant relationship was between stage and laterality, where the right side was found to have more advanced stage disease compared to the left $(\mathrm{p}=0.050)$.

\section{REFERENCES}

1. World Cancer Research Fund International. Breast cancer statistics. Breast Cancer Report 2012 - Incidence and Survival Rates. World Cancer Research Fund International, 2012. Available from: http://www.wcrf.org/int/cancer-facts-figures/ data-specific-cancers/breast-cancer-statistics/

2. African Cancer Registry Network. South African National Cancer Registry 2014. Available from: https://www.afcrn.org/ membership/members/87-ncrsa

3. Perkins CL, Hotes J, Kohler BA, Howe HL. Association between breast cancer laterality and tumor location, United 
States, 1994-1998. Cancer Causes Control. 2004;15(7):637-45.

4. Roychoudhuri R, Putcha V, Moller H. Cancer and laterality: a study of the five major paired organs (UK). Cancer Causes Control. 2006;17(15):655-62.

5. Weiss HA, Devesa SS, Brinton LA. Laterality of breast cancer in the United States. Cancer Causes Control. 1996;7(5):539-43.

6. Senie RT, Saflas AF, Brinton LA, Hoover RN. Is breast size a predictor of breast cancer risk or the laterality of the tumor? Cancer Causes Control. 1993;4(3):203-8.

7. Busk T, Clemmesen J. The frequency of left and right-sided breast cancer. Br J Cancer. 1947;1(4):345-51.

8. Zeeneldin AA, Ramadan M, Elmashad N, Fakhr I, Diaa A, Mosaad E. Breast cancer laterality among Egyptian patients and its association with treatments and survival. J Egypt Natl Canc Inst. 2013;25(4):199-207.

9. Melnik Y, Slater PE, Steinitz R, Davies AM. Breast cancer in Israel: laterality and survival. J Cancer Res Clin Oncol. 1979;95(3):291-3

10. Fatima N, Zaman MU, Maqbool A, Khan SH, Riaz N. Lower incidence but more aggressive behavior of right sided breast cancer in Pakistan women. Does right deserve more respect? Asian Pac J Cancer Prev. 2013;14(1):43-5.

11. Amer MH. Genetic factors and breast cancer laterality. Cancer Manag Res. 2014;6:191-203.

12. Tulinius H, Sigvaldason H, Olafsdottir G. Left and right sided breast cancer. Pathol Res Pract. 1990;186(1):192-4.

13. Ekbom A, Adami HO, Trichopoulos D, Lambe M, Hsieh CC, Ponten J. Epidermiologic correlates of breast cancer laterality (Sweden). Cancer Causes Control. 1994;5(6):510-6.

14. Ing R, Petrakis NL, Ho JH. Unilateral breast-feeding and breast cancer. Lancet. 977;310(8029):124-7.

15. Hsieh CC, Trichopoulos D. Breast size, handedness and breast cancer risk. Eur J Cancer Clin Oncol. 1991;27(2):131-5.

16. Sughrue T, Brody JP. Breast tumor laterality in the United States depends upon the country of birth, but not race. PLoS One. 2014 Aug;9(8):e103313.

17. Dane S, Yildirim S, Koc M, Aktan M, Gundogdu C. Asymmetries in breast cancer lateralization and both axillary lymph node number and metastatic involvement. Lymphology. 2008;41(2):75-9.

18. Dmitrenko A P. Lateral differences in $\mathrm{Ki}-67$ in breast cancer. Mol Clin Oncol. 2016;4(6):1041-4.

19. Yun-Jiu Cheng, Xiao-Ying Nie, Cheng-Cheng J et al. Longterm cardiovascular risk after radiotherapy in women with breast cancer. J Am Heart Assoc. 2017;6:e005633.

20. Rutqvist L E, Johansson H. Mortality by laterality of the primary tumour among 55000 breast cancer patients from the Swedish Cancer Registry. Br J Cancer 1990;61(6):866-8.

21. Harris E E, Correa C, Hwang W-T, et al. Late cardiac mortality and morbidity in early-stage breast cancer patients after breast conservation treatment. J Clin Ocol. 2006;24(25):4100-6.

22. Rutter CE, Chaqpar AB, Evan SB. Breast laterality does not influence survival in a large modern cohort: implication for radiation related cardiac mortality. International Journal of Radiation Oncology* Biology* Physics. 2014;90(2):329-34.

23. Mutebi M, Simonds H, Cairncross L, Panieri H. Breast ductal carcinoma in situ in an unscreened population: presentation, diagnosis and management at a single tertiary centre. S Afr J Surg. 2017;55(1):4-9.

24. American Cancer Society. Cancer facts and figures; 2015. Available from: https://www.cancer.org/content/dam/cancerorg/research/cancer-facts-and-statistics/annual-cancer-factsand-figures/2015/cancer-facts-and-figures-2015.pdf 